\title{
The interface of $\sigma$ with core RNA polymerase is extensive, conserved, and functionally specialized
}

\author{
Meghan M. Sharp, ${ }^{1}$ Cathleen L. Chan, ${ }^{1}$ Chi Zen Lu, ${ }^{1}$ Michael T. Marr, ${ }^{2}$ Sergei Nechaev, ${ }^{3}$ \\ Ernest W. Merritt, ${ }^{4}$ Konstantin Severinov, ${ }^{3}$ Jeffrey W. Roberts, ${ }^{2}$ and Carol A. Gross ${ }^{1,5}$ \\ ${ }^{1}$ University of California, San Francisco, San Francisco, California 94143 USA; ${ }^{2}$ Section of Biochemistry, Molecular and Cell \\ Biology, Cornell University, Ithaca, New York 14853 USA; ${ }^{3}$ Department of Genetics, Waksman Institute, Rutgers, The State \\ University of New Jersey, Piscataway, New Jersey 08854 USA; ${ }^{4}$ Proctor and Gamble Pharmaceuticals, Health Care Research \\ Center, Mason, Ohio 45040 USA
}

The $\sigma$ subunit of eubacterial RNA polymerase is required throughout initiation, but how it communicates with core polymerase $\left(\alpha_{2} \beta \beta^{\prime}\right)$ is poorly understood. The present work addresses the location and function of the interface of $\sigma$ with core. Our studies suggest that this interface is extensive as mutations in six conserved regions of $\sigma^{70}$ hinder the ability of $\sigma$ to bind core. Direct binding of one of these regions to core can be demonstrated using a peptide-based approach. The same regions, and even equivalent residues, in $\sigma^{32}$ and $\sigma^{70}$ alter core interaction, suggesting that $\sigma^{70}$ family members use homologous residues, at least in part, to interact with core. Finally, the regions of $\sigma$ that we identify perform specialized functions, suggesting that different portions of the interface perform discrete roles during transcription initiation.

[Key Words: $\sigma$ factor; core; RNA polymerase; transcription; initiation; pausing]

Received August 24, 1999; revised version accepted October 5, 1999.

In prokaryotic cells, the $\sigma$ subunits of RNA polymerase direct the process of transcription initiation. Bacterial cells utilize one primary $\sigma$, called $\sigma^{70}$ in Escherichia coli, to direct transcription of housekeeping genes during exponential growth. In addition, most bacteria have several alternative $\sigma \mathrm{s}$, each of which directs transcription of a specific set of genes in response to either environmental or developmental signals. The primary $\sigma$ s and almost all alternative $\sigma$ s constitute a homologous set of proteins, the $\sigma^{70}$ family of proteins. E. coli contains six members of this family and one additional $\sigma, \sigma^{54}$, which is unrelated in sequence or mechanism to the $\sigma^{70}$ protein family (Lonetto et al. 1992). The conserved regions of the $\sigma^{70}$ family are shown in Figure 1D (Helmann and Chamberlin 1988; Lonetto et al. 1992; Wosten 1998).

For $\sigma^{70}$-type $\sigma s$, the process of transcription initiation begins when $\sigma$ binds to core RNA polymerase $\left(\alpha_{2} \beta \beta^{\prime}\right)$ to form RNA polymerase holoenzyme $\left(\alpha_{2} \beta \beta^{\prime} \sigma\right)$. As a result of this interaction, both partners undergo major conformational changes and become competent for initiation. For $\sigma$, this involves exposure and reorientation of its DNA-binding domains so that it can specifically recognize the two conserved hexamers that constitute the prokaryotic promoter (Dombroski et al. 1992, 1993; Callaci and Heyduk 1998; Callaci et al. 1999). For core RNA

${ }^{5}$ Corresponding author.

E-MAIL cgross@cgl.ucsf.edu; FAX (415) 476-4204. polymerase (core), a channel with dimensions large enough to fit duplex DNA that is closed in core opens in the holoenzyme form of the enzyme (Polyakov et al. 1995). Despite the interface's importance in facilitating these conformational changes, little is known about the contacts between $\sigma$ and core polymerase. In this report, we identify residues in $\sigma^{70}$ that are important for interaction with core and discuss their functional significance.

Previous studies have identified conserved region 2.1 of $\sigma$ as an important determinant of core binding. Deletion derivatives of $\sigma^{70}$ and $\sigma^{32}$ of $E$. coli lacking region 2.1 were unable to bind to core, as was a single point mutation in region 2.1 of the $\sigma^{70}$ family member $\sigma^{\mathrm{E}}$ in Bacillus subtilis (Lesley and Burgess 1989; Lesley et al. 1991; Shuler et al. 1995). In addition, the only short stretch of amino acids in $\sigma^{54}$ that seems homologous to $\sigma^{70}$ corresponds to a portion of region 2.1. This portion of $\sigma^{54}$ is implicated in core binding as well (Tintut and Gralla 1995).

Additional regions of $\sigma$ have also been suggested to interact with core. A recent genetic analysis of $\sigma^{32}$ found residues in four conserved regions (but not region 2.1) that were involved in interaction with core (Joo et al. 1997, 1998). Protein footprinting studies of $\sigma^{70}$ and gp55 (a small, divergent, T4 phage-encoded $\sigma$ ) suggested that several regions of these $\sigma \mathrm{s}$ are protected on interaction with core (Nagai and Shimamoto 1997; Leonetti and Gei- 
A

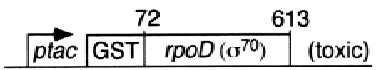

B
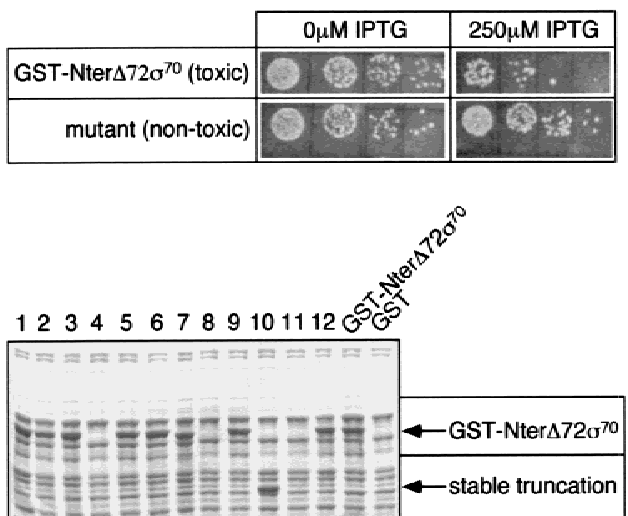

D

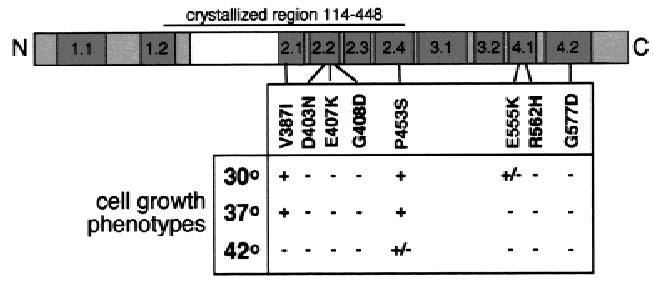

Figure 1. Selection for $\sigma^{70}$ mutants defective in $\sigma$-core interaction. (A) A schematic of the toxic $\sigma$ variant mutagenized with hydroxylamine. $(B)$ Serial dilutions of cells with a toxic or nontoxic variant of $\sigma^{70}$. DH5 $\alpha$ cells containing either the toxic GST-Nter $\Delta 72 \sigma^{70}$ fragment or a nontoxic hydroxylamine-generated mutant variant were plated with (right) or without (left) expression of the $\sigma$ variants. (C) SDS gel analysis of hydroxylamine-generated nontoxic variants of GST-Nter $\Delta 72 \sigma^{70}$. Cells were grown at $30^{\circ} \mathrm{C}$ in $\mathrm{LB}$ to an $\mathrm{OD}_{600}=0.5$, induced with $1 \mathrm{~mm}$ IPTG for $1 \mathrm{hr}$, lysed by resuspending in sample loading buffer and boiling for $5 \mathrm{~min}$, and loaded on an $8 \%$ SDS Tris-glycine gel. The unstable (lanes 4,8,11) and truncated (lane 10) variants were discarded. $(D)$ Location of mutations in $\sigma^{70}$ and their cell-growth phenotypes. A linear diagram of $\sigma$ indicates the four conserved regions, which have the following functional assignments: Region 1.1, autoinhibition of DNA binding; regions 2.3-2.4, DNA melting and -10 region promoter recognition; region $4.2,-35$ region promoter recognition and activator response. Position of mutants is indicated below the linear diagram. Ability of the mutant plasmid-encoded $\sigma$ s to support cell growth was determined by comparing plating efficiency with and without expression of chromosomal $\sigma$ at three different temperatures.

duschek 1998). Finally, genetic analysis suggests that Mftflp (a distantly related promoter specificity factor in yeast mitochondrial RNA polymerase) uses amino acids in regions homologous to conserved regions 2 and 3 of $\sigma^{70}$ to interact with its single subunit core polymerase (Cliften et al. 1997).

We used an unbiased genetic approach as well as directed changes to identify residues in $\sigma^{70}$ that are important for interaction with core. Our genetic studies indicate that residues in several conserved regions of $\sigma$ are important for this interaction, indicating that the interface is extensive. One of these regions is also identified by a peptide inhibition approach. Our results indicate that the same regions and even the same residues in two different $\sigma \mathrm{s}$ alter this interaction, suggesting that $\sigma^{70}$ family members use homologous residues, at least in part, to interact with core. We show further that the interface of $\sigma$ with core is functionally specialized, as certain functions are localized to particular regions of the interface.

\section{Results}

Selection for $\sigma^{70}$ mutants defective in binding core RNA polymerase

GST fused to the amino terminus of a $\sigma^{70}$ derivative lacking its first 72 amino acids (GST-Nter $\Delta 72 \sigma^{70}$; Fig. $1 \mathrm{~A})$ is toxic to the cell when overexpressed. RNA polymerase containing this $\sigma$ fusion protein has a severe defect in open complex formation, suggesting that toxicity results from sequestering core RNA polymerase in a nonproductive holoenzyme complex (Wilson and Dombroski 1997). We reasoned that $\sigma^{70}$ mutants defective in binding to core would relieve the toxicity of GSTNter $\Delta 72 \sigma^{70}$.

Following hydroxylamine mutagenesis, $\sim 300$ of 120,000 colonies showed decreased toxicity on overexpression of GST-Nter $\Delta 72 \sigma^{70}$ (Fig. 1B). To screen out mutations that relieved toxicity because they encoded either truncated or misfolded $\sigma \mathrm{s}$, we examined 90 of the mutant $\sigma s$ on SDS-polyacrylamide gels (Fig. 1C). About half of the $\sigma$ s were either unstable, indicating that they were misfolded (Fig. 1C, lanes 4,8,11), or truncated (Fig. 1C, lane 10). These mutants were discarded. Twenty-five of the remaining mutants were cloned back into GSTNter $\Delta 72 \sigma^{70}$ to confirm their phenotype. The 20 mutants that relieved toxicity when recloned were sequenced. Ten of these proved to be point mutations in $\operatorname{rpoD}\left(\sigma^{70}\right)$. The others either did not have a detectable base change within $r p o D\left(\sigma^{70}\right)$ or produced truncations at the very carboxyl terminus that had escaped our initial screen.

The ten mutations were located in five different conserved regions of $\sigma^{70}$; one in region 2.1, three in region 2.2 , one in region 2.4 , two in region 4.1 , and one in region 4.2 (Fig. 1D). Two mutations, D403N and E407K, were isolated twice, implying that these residues were mutational hot spots or that we were approaching saturation in the mutagenesis. The eight remaining $\sigma^{70}$ mutants potentially defective in $\sigma$-core interaction were cloned into a construct expressing his-tagged full-length $\sigma^{70}$.

We used a strain whose chromosomal copy of $\sigma^{70}$ is regulated by the $\operatorname{trp}$ promoter to assess the ability of the plasmid-encoded mutant $\sigma$ factors to support cell growth. When chromosomal $\sigma^{70}$ was shut off, one of the mutant $\sigma$ s supported growth at all temperatures tested, a second was defective at high temperature only, and the remaining six were unable to support cell growth at any temperature tested (Fig. 1D). Two of the mutations changed glycine residues located at positions 408 and 577. We did not analyze the phenotypes of the glycine mutants further, as such changes are likely to perturb the structure of the protein. 
A competitive binding assay demonstrates that the mutant os are defective in binding to core

We developed a competitive binding assay and then used it to examine the ability of the $\sigma^{70}$ mutants to bind core. Increasing amounts of nonradioactive $\sigma^{70}$ were mixed with a fixed amount of radioactive wild-type $\sigma^{70}\left(\sigma^{70^{*}}\right)$ and allowed to bind to a limiting amount of core. The complexes were separated by immunoprecipitation with an antibody directed against core and then analyzed for the amount of radioactive $\sigma^{70}$ present. Order of addition experiments performed over a 10-fold range (10-100 nM $\sigma^{70^{*}}$ ), showed that this assay is in equilibrium (Fig. 2A; data not shown). A titration with increasing amounts of nonradioactive wild-type $\sigma^{70}$ indicates that the assay is well behaved over the entire experimental range (Fig. $2 B)$. We can reliably quantify our results in the range of
$25 \%-90 \%$ of $\sigma^{70^{*}}$ competed, thus setting upper and lower limits for the assay.

To determine the binding of each mutant $\sigma$ relative to wild-type $\sigma$, we competed $\sigma^{70^{*}}$ with a twofold and fivefold excess of nonradioactive mutant $\sigma^{70}$. Each of the mutants competes more poorly than wild-type $\sigma^{70}$ (Fig. 2C). We excluded two trivial possibilities for lack of competition by mutant $\sigma$ s. First, we show that addition of wild-type $\sigma^{70}$ restored competition, eliminating the possibility that the high recovery of $\sigma^{70^{*}}$ resulted from aggregation of $\sigma^{70^{*}}$ with the mutant $\sigma s$ (Fig. 2C). Second, we used two independent assays to show that the purified mutant $\sigma^{70}$ proteins were approximately as active as wild-type $\sigma^{70}$. Both a noncompetitive binding assay performed with core in excess and a transcription assay (see Materials and Methods), indicated that $\geq 50 \%$ of the mutant $\sigma$ was active (M. Sharp, data not shown). We con-
A

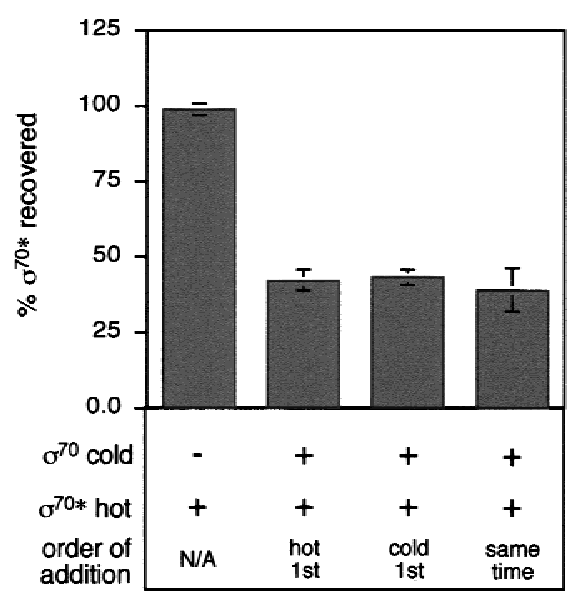

C

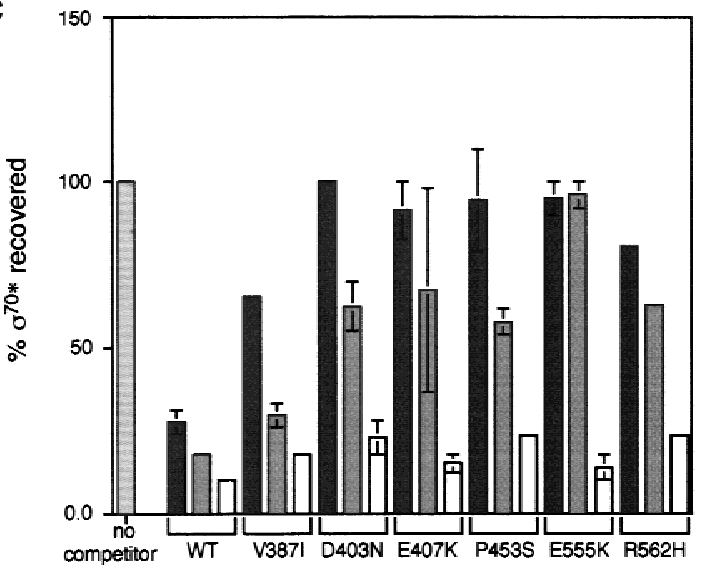

B

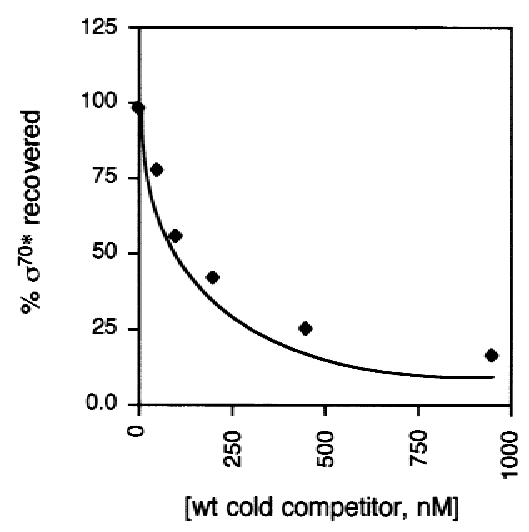

D

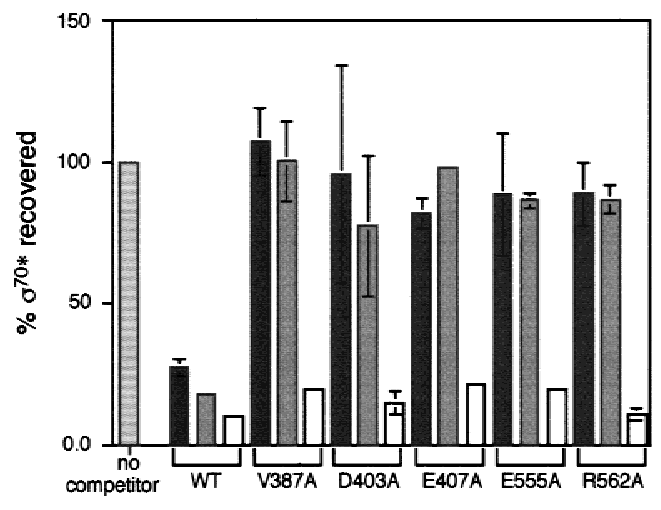

Figure 2. A coimmunoprecipitation competition assay measures $\sigma$ binding to core polymerase. $(A)$ The $\sigma$-core-binding assay is in equilibrium. When a twofold excess of nonradioactive wild-type $\sigma^{70}$ competitor is added after (lane 2), before (lane 3), or at the same time as (lane 4) $100 \mathrm{nM}$ wild-type $\sigma^{70}$ labeled with $\left[\gamma_{-}{ }^{32} \mathrm{P}\right] \mathrm{ATP}$, equivalent competition for binding to core is observed (see Materials and Methods for details of the assay). (B) A titration with wild-type $\sigma^{70}$ competitor. 100 nM-labeled wild-type $\sigma^{70^{*}}$ was competed against 1-1000 nM cold $\sigma^{70}$ competitor $(\bullet)$ for binding to core. Experimental data compares well with the theoretical curve. $(C)$ Relative binding of the mutant $\sigma$ s to core determined from the coimmunoprecipitation competition assay. Wild-type $\sigma^{70^{*}}$ was competed against a twofold (dark gray bars) or fivefold (light gray bars) excess of wild-type or mutant $\sigma^{70}$ for binding to core. Competition with a fivefold excess of both mutant and wild-type $\sigma^{70}$ is indicated by white open bars. $(D)$ Relative binding of $\sigma^{70}$ alanine substitution derivatives. Symbols and protocols as in Fig. 2C. 
Sharp et al.

Table 1. Estimation of the core binding defects of $\sigma^{70}$ mutants

\begin{tabular}{llll}
\hline R374A & 1.0 & L598A & 13.0 \\
K392A & 1.0 & N409D & 15.0 \\
V387I & 2.0 & L384A & $>15$ \\
I405A & 2.0 & V387A & $>15$ \\
I388A & 3.0 & D403A & $>15$ \\
F401A & 3.0 & Q406A & $>15$ \\
P453S & 7.0 & E407A & $>15$ \\
P504A & 8.0 & M413T & $>15$ \\
D403N & 9.0 & E555K & $>15$ \\
R562H & 9.0 & E555A & $>15$ \\
L402F & 10.0 & R562A & $>15$ \\
E407K & 11.0 & I565A & $>15$ \\
\hline
\end{tabular}

Data generated from competition with a 5 -fold excess of mutant $\sigma$ was compared to a standard curve generated with increasing concentrations of wild-type $\sigma$ (Fig. 2B). We express the defect in terms of wild-type $\sigma$ equivalents, that is, how much more mutant than wild-type protein is required to achieve the same amount of competition. The binding defects calculated from a two-fold excess of mutant $\sigma$ were similar to those reported above. Binding defects 15 -fold or greater cannot be reliably distinguished (see text).

clude that the mutants are specifically defective in binding to core.

The binding assay data can be quantified by comparing the concentrations of wild-type and mutant $\sigma^{70}$ required for equivalent competition. For example, when $450 \mathrm{~nm}$ mutant competes as if it were present at $30 \mathrm{~nm}$ wild-type, the mutant has a 15-fold defect in core binding. Experimental limits prevent us from quantifying defects $>15$ fold. Five of the six $\sigma^{70}$ mutant proteins exhibited defects ranging from 7 -fold to $>15$-fold in binding core RNA polymerase (Table 1). The last mutant, V387I had little or no binding defect.

Our mutants could directly disrupt the interaction between $\sigma$ and core by removing a favorable interaction or by creating a steric clash. We eliminated steric clashes by changing the mutated residues to alanine. Alanine substitutions are also less likely to perturb the hydrophobic core, although in our case, the crystal structure of a fragment of $\sigma^{70}$ indicates that two of the affected residues (D403 and E407) are surface exposed. Two additional mutants alter charged residues, suggesting that they are also surface exposed. Only one residue, V387, is partially buried.

All of the alanine substitution mutant proteins (V387A, D403A, E407A, E555A, and R562A) had binding defects equal to or greater than that of the original $\mathrm{mu}-$ tants (Fig. 2D; Table 1), and had activities within twofold of wild-type $\sigma^{70}$ in a transcription assay (see Materials and Methods), suggesting that the original mutants removed favorable interactions with residues in core. Alanine substitutions of putative surface-exposed residues may remove favorable interactions, present in the original mutant changes, thus explaining their increased severity. For example, the histidine substitution at R562 might maintain some of the interactions normally provided by an arginine side chain, whereas the alanine substitution would have none of these contacts.
Regions of $\sigma^{70}$ and $\sigma^{32}$ that affect binding to core are highly conserved

Using a genetic approach, Joo and Calendar had previously identified residues in $\sigma^{32}$ important for interaction with core (Joo et al. 1997, 1998). For both $\sigma^{70}$ and $\sigma^{32}$, multiple residues in both regions 2.2 and 4.1 were implicated in binding to core, indicating that both $\sigma$ s share some similarities in their core binding surfaces. However, the $\sigma^{32}$ selection and our $\sigma^{70}$ selection had also identified different regions. For $\sigma^{70}$, residues in regions 2.1 and 2.4 have a core-binding defect, although the V387A change could be perturbing the structure of the protein. For $\sigma^{32}$, residues in regions 3.1, 4.2, and a region unique to $\sigma^{32}$ (the $\mathrm{RpoH}$ box) have core-binding defects (Fig. 3A). We chose one residue implicated in core binding from each of the four regions in $\sigma^{32}$ that are conserved in $\sigma^{70}$, mutated the comparable residue in $\sigma^{70}$ to alanine, and tested core binding. Q406A, P504A, I565A, and L598A are all defective (Fig. 3B; Table 1). Therefore, these residues are important for both $\sigma^{70}$ and $\sigma^{32}$ interaction with core RNA polymerase.

\section{Q406N and E407K abolish the inhibitory effect of a $\sigma$-derived peptide on transcription}

Region 2.2 of $\sigma^{70}$ had been independently implicated in binding to core by S. Roychoudhury, F. Wang, E.W. Mer-
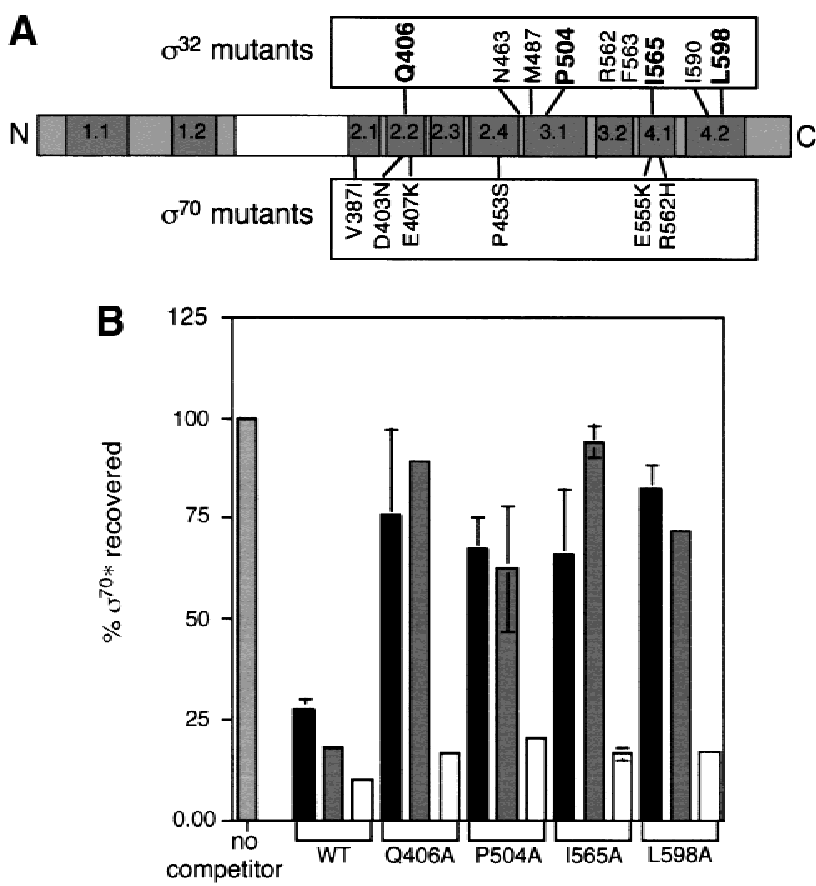

Figure 3. Derivation and binding properties of a second set of $\sigma^{70}$ alanine substitution mutations. (A) Comparison of the residues in $\sigma^{70}$ and $\sigma^{32}$ shown to be important for interaction with core polymerase. The $\sigma^{32}$ mutant changes reconstructed as alanine substitutions in equivalent $\sigma^{70}$ residues are indicated in boldface. $(B)$ Relative binding of mutant $\sigma s$ to core determined from the coimmunoprecipitation competition assay. Symbols and protocols as in Fig. 2C. 
ritt, E.P. Rennells, C. Kasibhatla, and C.N. Parker (unpubl.), who showed that a small peptide spanning residues 390-407 of $\sigma^{70}$ (SF2.4) inhibited transcription by holoenzyme. This includes part of regions 2.1 and 2.2 and three (D403, Q406, and E407) of the residues identified in our mutational study as important for core binding. We made three peptides, each having a different mutational change, and determined whether they could relieve inhibition. As measured by abortive initiation, two of the three peptides, SF2.4-Q406N and SF2.4-E407K inhibited formation of the abortive trimer, $\mathrm{CpApU}$, less than the wild-type peptide (Fig. 4A, cf. lanes 8, 9, 11, and 12 with lanes 2 and 3). In each case, excess wild-type $\sigma^{70}$ overcomes the inhibitory effect of the peptide (Fig. 4A). Together, these results support the view that this peptide inhibits transcription by competing for authentic $\sigma$-binding sites on core. Consistent with this idea, a gelshift assay carried out at $0^{\circ} \mathrm{C}$ shows that the inhibitory peptide worked at an early step of transcription, preventing formation of the closed complex (Fig. 4B). As expected, both excess $\sigma$ and attenuation by mutational alteration relieves inhibition (Fig. 4B).

\section{Mutants in regions 2.1 and 2.2 of $\sigma^{70}$ reduce a promoter proximal pause required for $\lambda Q$ function}

We had described previously four $\sigma^{70}$ mutants (L402F, Q406A, N409D, and M413T) that are specifically defective in $\lambda \mathrm{Q}$-mediated antitermination because they failed to establish the pause required for Q to function (Ko et al. 1998). These mutants were located very close to the mutants we isolated in regions 2.1 and 2.2, and an in vivo assay had suggested that two of these mutants were defective in core interaction. All of these mutants have severe core-binding defects in our in vitro assay (Fig. 5A; Table 1), which are of greater magnitude, but the same rank order as those estimated from the in vivo assay (Ko et al. 1998). The less severe binding defects measured in vivo could result from the indirect nature of the in vivo assay, or from the many differences in conditions between the two assays. In particular, in the rapid initiation conditions present in the cell, nucleotide addition may be faster than dissociation, so that only the forward rates of $\sigma$ binding to core contribute to competition.

We wondered whether a defect in producing paused transcripts from the $p R^{\prime}$ promoter was characteristic of all mutants with reduced binding to core or limited to $\sigma^{70}$ mutants in regions 2.1 and 2.2. The latter proved to be the case. Only the region 2.1 and 2.2 mutants (V387I, $\mathrm{D} 403 \mathrm{~N}$, and $\mathrm{E} 407 \mathrm{~K}$ ) were significantly defective, reducing both the fraction of RNA polymerase that pauses and the pause half-life (Fig. 5B). Our region 2.4 mutant (P453S) and the two region 4.1 mutants (E555K and $\mathrm{R} 562 \mathrm{H})$ had little or no effect on pausing at $\lambda p R^{\prime}$.

\section{Another potential binding surface in $\sigma^{70}$ has little or no effect on holoenzyme formation}

On the basis of genetic analysis that included a singlepoint mutant in $\sigma^{\mathrm{E}}$ in $B$. subtilis at a position homolo-
A
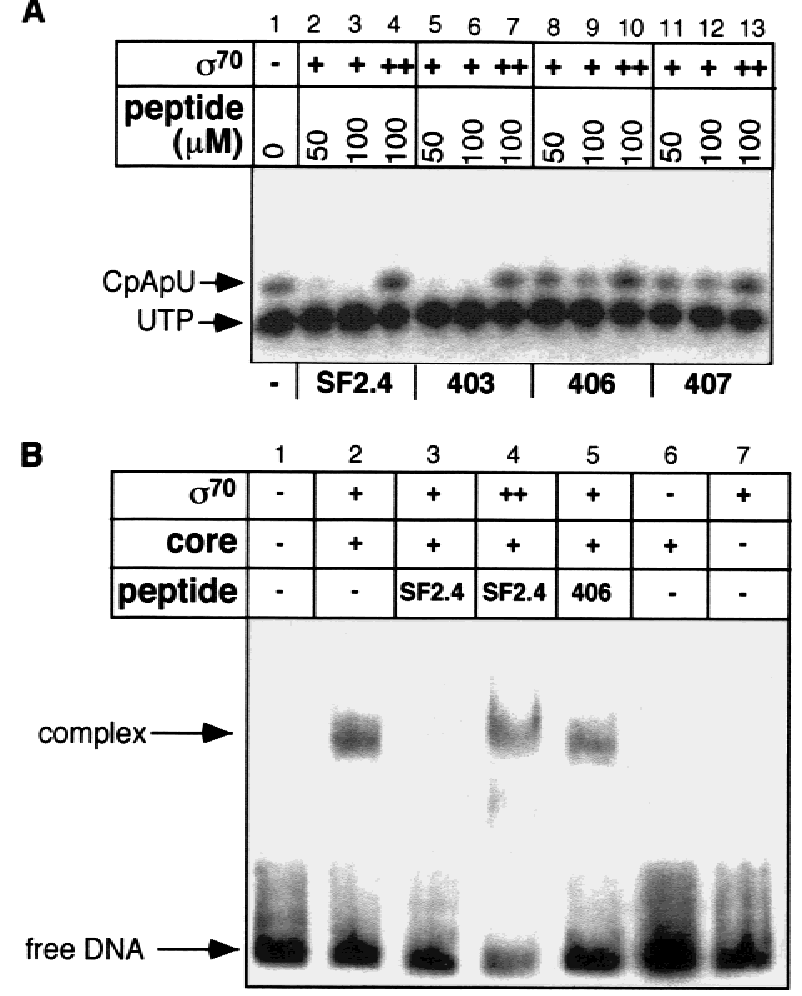

Figure 4. Inhibition of $\sigma$-core interactions by synthetic peptides spanning 390-407 of $\sigma^{70}$. (A) The effect of synthetic $\sigma$ factor peptide, SF2.4 (amino acids 390-407 of $\sigma^{70}$ ), on $\sigma^{70}$-dependent abortive initiation. SF 2.4 peptide containing either the wild-type sequence (lanes 2-4), the D403N substitution (lanes 5-7), the Q406A substitution (lanes 8-10), or the E407K substitution (lanes 11-13) were combined with 0.2 pmole RNAP core enzyme and 0.1 pmole $\sigma^{70}$ (lane 1) and assessed for their ability to make a CpApU abortive transcript from $20 \mathrm{ng}$ of a 130-bp DNA fragment containing T7A1 promoter (see Materials and Methods). The first two lanes in each set of three show the effect of increasing concentration of peptide on abortive initiation; the third lane assesses the effect of a fivefold molar excess of $\sigma$ relative to core on peptide inhibition. The SF2.4 peptide inhibits transcription (lanes 2,3); this inhibitory effect is ameliorated by the Q406A and E407K substitutions (lanes 8,9,11,12) but not by the D403N substitution (lane 5,6). Excess $\sigma$ overcomes inhibition (lanes 4,7,10,13). (B) SF2.4 peptide prevents the formation of the closed promoter complex. RNAP core enzyme was incubated with SF2.4 peptide and $\sigma^{70}$ as in $A$, transferred to ice, and incubated with a ${ }^{32}$ P-labeled 130-bp DNA containing the T7A1 promoter for $30 \mathrm{~min}$. Promoter-RNA polymerase complexes were resolved on nondenaturing polyacrylamide gels and visualized (see Materials and Methods).

gous to R385 of $\sigma^{70}$ and deletions in region 2.1 that altered the ability of both $\sigma^{70}$ and $\sigma^{32}$ to bind core, it was thought that region 2.1 of $\sigma^{70}$ was a primary determinant for binding to core (Lesley and Burgess 1989; Lesley et al. 1991; Shuler et al. 1995). On analysis of the crystal structure of a fragment of $\sigma^{70}$, Darst and colleagues proposed that five highly conserved exposed hydrophobic residues and two highly conserved charged residues in regions 2.1 and 2.2 might interact with core (Malhotra et al. 1996). Thus, we wondered if these other solvent-exposed resi- 
A

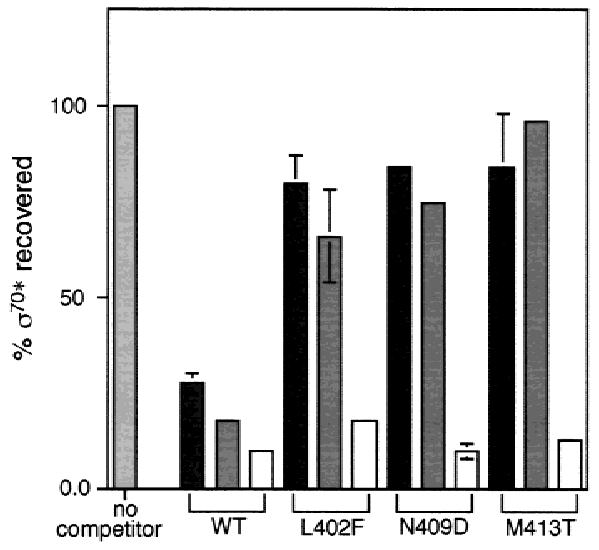

B

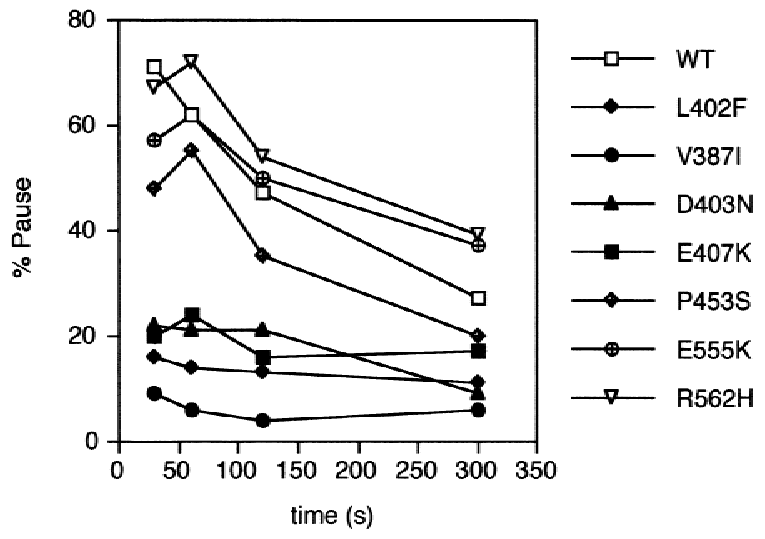

Figure 5. Phenotypes of $\sigma$ mutants. (A) Relative core binding of $\sigma^{70}$ mutants defective in promoter-proximal pausing. Symbols and protocols as in Fig. 2C. $(B)$ Effects of $\sigma$ mutants on promoter proximal pausing. Each mutant $\sigma$ was assessed in vitro for the ability to facilitate the pause in transcription that occurs at +16 after initiation at the $\lambda P_{R}$ promoter. Transcription reactions were sampled at $0.5,1,2$, and $5 \mathrm{~min}$.

dues of $\sigma^{70}$ interacted with core. We made alanine substitutions at four highly conserved hydrophobic residues (L384A, I388A, F401A, and I405A) and at the two highly conserved charged residues (R374A and K392A) proposed to interact with core (Malhotra et al. 1996). With the exception of L384A, these mutants had little or no defect in core binding (Fig. 6; Table 1) and therefore, at least under the conditions of our assay, interactions with these residues are not required for holoenzyme formation. The fifth highly conserved hydrophobic residue had already been identified in our selection for mutants defective in $\lambda Q$ antitermination. This mutant is also defective in core binding as shown in Figure 5. Interestingly, the two mutants with core-binding defects (L384 and L402) are both located within the cluster of mutations that we have defined (see Fig. 7A).

\section{Discussion}

Two complementary genetic approaches allowed us to identify residues in $\sigma^{70}$ that are important for interaction with core. An unbiased genetic selection (Fig. 1) as well as site-directed mutagenesis of residues implicated in core binding identified a patch of amino acids composed almost entirely of residues from region 2.2 as well as other residues located in regions $2.4,3.1,4.1$, and 4.2 that are important for interaction of $\sigma^{70}$ with core RNA polymerase. Also, transcription inhibition by a small peptide from region 2.2 is relieved by two of our mutational changes that reduced core binding. It is possible that some of the amino acid substitutions indirectly affect $\sigma$ binding to core, for example, by stabilizing a protein conformation unfavorable for binding to core. However, our genetic experiments, in combination with other data, provide strong reason to believe that the regions we have identified directly contact core. These same amino acid substitutions alter interaction of $\sigma$ with selected fragments of core in a yeast two-hybrid analysis (T. Gruber and C. Gross, unpubl.). Moreover, each residue we have identified is located in a region of $\sigma^{70}$ that is protected from cleavage when bound to core (Nagai and Shimamoto 1997). We suggest that these regions (and possibly others) constitute the interface used by the $\sigma^{70}$ family of proteins to interact with core RNA polymerase and modulate initiation. Our experiments indicate that this interface is functionally specialized.

\section{Much of the $\sigma^{70}$ and $\sigma^{32}$ interface with core is highly conserved}

The six members of the E. coli $\sigma^{70}$ family of proteins all bind to the same core RNA polymerase with different affinities. As core is limiting in the cell, competition among $\sigma$ factors could exert global control over gene expression (Osawa and Yura 1981; Ingraham et al. 1983; Ishihama 1991; Zhou and Gross 1992). To understand how different $\sigma$ s bind core, we asked whether residues implicated in $\sigma^{32}$ binding to core were also important for $\sigma^{70}$ binding. In each of the four cases tested /one residue

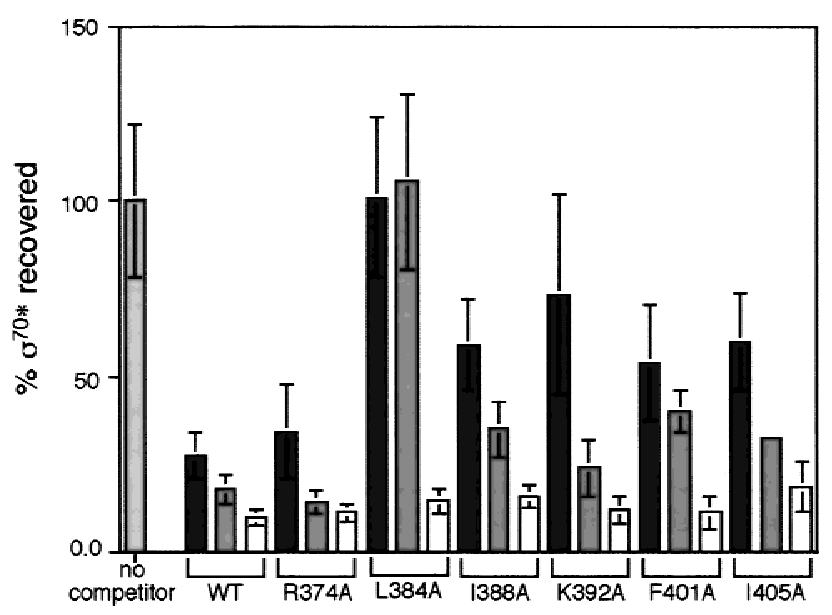

Figure 6. Relative core binding properties of alanine substitution $\sigma^{70}$ mutants located in region 2.1. Symbols and protocols as in Fig. 2C. 

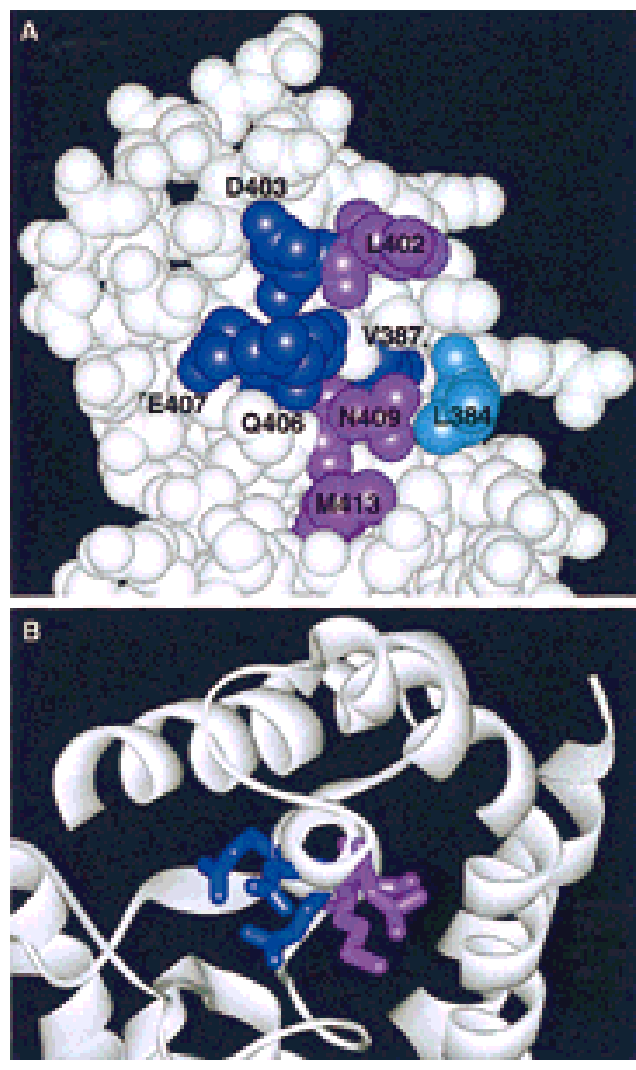

Figure 7. Location on the crystal structure of the $\sigma^{70}$ residues implicated in core binding. (A) A space-filling model indicates residues from regions 2.1 and 2.2 implicated in core binding. Residues in dark purple were identified by genetic selection for relief of toxicity (V387, D403, and E407) or by a comparable $\sigma^{32}$ selection (Q406); those in light purple were identified because of their defect in Q-mediated antitermination (L402, N409, and M413); the residue in cyan was proposed from the crystal structure (L384) (Malhotra et al. 1996). (B) A view of the $\sigma^{70}$ crystal structure looking down or through helix 13 (region 2.2) showing that the region 2.2 mutants from the two different selections (indicated by light and dark purple) are localized on two different faces of the helix.

from each conserved region of $\sigma^{32}$ implicated in binding), the $\sigma^{70}$ mutants were also very defective in core binding. These results suggest that all $\sigma^{70}$ family members use homologous regions and possibly, in some cases, homologous residues when binding to core. However, $\sigma \mathrm{s}$ also use nonhomologous regions for this interaction. Both the RpoH box and region 1.1, unique to $\sigma^{32}$ and $\sigma^{70}$ respectively, contain core-binding determinants (Joo et al. 1998; T. Gruber and C. Gross, unpubl.). The combination of conserved and nonconserved surfaces for interaction may contribute to the functional specialization of each $\sigma$ factor.

\section{Mutational analysis suggests that the $\sigma^{70}$ interface with core is extensive}

The core-interaction site that we have defined most completely is a patch of residues on the crystal structure of a fragment of $\sigma^{70}$ consisting almost entirely of residues from region 2.2 with contributions from two nearby residues in region 2.1. Among the residues identified, only one (V387) is partially buried in the hydrophobic core; all others, including three hydrophobic residues (L402 and M413 in region 2.2 and L384 in region 2.1), are surface exposed and available to interact with core (Fig. 7). A small peptide (residues 390-407) that includes four of these residues (L402, D403, Q406, and E407) inhibits formation of the closed complex and abortive initiation by binding to core competitively with $\sigma$. The simplest interpretation of this result is that inhibition results from occlusion of sites on core that bind $\sigma$. The fact that peptides with a Q406N or E407K substitution show reduced inhibition validates this idea, thereby providing direct evidence that Q406 and E407, and by extension, this entire patch of residues directly contact core. The third substitution, D403N, showed severe core-binding defects only in intact $\sigma^{70}$. This mutation may inhibit core binding by destabilizing the entire cluster, an effect that would be unlikely to occur in the small peptide that lacks the structural constraints of the intact molecule.

The region 2.2 interaction patch includes mutants obtained from two different types of genetic selections, one on the basis of defects in Q-mediated antitermination (L402F, N409D, and M413T) and the other on the basis of the ability of a toxic fragment of $\sigma$ to compete with authentic $\sigma$ for forming productive holoenzyme (D403, E407, and Q406). Both classes of mutants are comparable in their defects in core binding in vitro, but only the former class is viable. Interestingly, an axial view of helix 13, which comprises most of region 2.2, reveals that each mutant class is in a slightly different location, with the Q-defective class slightly to the right of the other class (Fig. 7B). Further examination of the two groups of mutants may reveal additional differences in their function.

In addition to this well-defined patch, residues in regions 2.4, 3.1, 4.1, and 4.2 also reduce interaction of $\sigma$ with core. When the residues shown to be important for both $\sigma^{70}$ and $\sigma^{32}$ binding to core are included, the mutationally defined core-interacting surface of region 4.1 is defined by four closely spaced residues (E555, R562, F563, and I565) and that of 4.2 is defined by two residues (I590 and L598). By use of this same criterion, and including as well a substitution in $\sigma^{70}$ that has been shown by glycerol gradient sedimentation to have a decreased affinity for core, the mutationally defined core interaction surface of region 3.1 includes three residues (M487, P504, and S506) (Hernandez and Cashel 1995; Joo et al. 1998). Because all of the alanine-substitution mutants we tested retain the core-binding defects of the original mutations, we favor the idea that the originally selected mutations disrupted existing interactions rather than creating unfavorable interactions with residues in core.

Other data suggests that additional regions of $\sigma^{70}$ interact with core. The fusion protein used to select mutations lacked the first 71 amino acids of $\sigma^{70}$, and could not be used to assess the role of region 1.1 in core bind- 
ing. Evidence from an independent approach that relies on a yeast two-hybrid analysis indicates that region 1.1 does interact with core (T. Gruber and C. Gross, unpubl.). Consistent with this idea, protein footprinting data suggests burial of region 1.1 on holoenzyme formation (Nagai and Shimamoto 1997). Furthermore, neither the selection for mutants in $\sigma^{32}$ nor our selection for mutants in $\sigma^{70}$ were saturating. Because hydroxylamine only makes guanine/cytosine to adenine/thymine transitions, it is likely that we were unable to identify several residues important for core interaction. Therefore, conserved regions other than those identified could be important for binding core.

Finally, as holoenzyme undergoes major conformational changes during transcription initiation, it is likely that contacts between $\sigma$ and core change during initiation. Because our binding assay identifies only those mutants defective in forming the initial interface, other in vitro techniques will be required to identify such contacts. On the basis of genetic analysis, region 2.1 had been previously considered to be a major core-binding determinant (Lesley and Burgess 1989; Shuler et al. 1995). Yet the point mutations we have tested have only little or no binding defects when tested under the conditions of our competitive binding assay. Region 2.1 is an excellent candidate for a core contact surface utilized later in initiation, as mutants in this region do manifest a variety of cell growth phenotypes and transcriptional defects. For example, F401A has $<5 \%$ of the transcriptional activity of wild type in a single-round transcription experiment ( $M$. Sharp, data not shown), but has little or no defect in binding core. Although these residues have no obvious role in forming the initial interface, they could quite possibly contact core during later steps of initiation.

Comparison of the residues of the $B$. subtilis $\sigma$ factor, $\sigma^{\mathrm{F}}$, required for binding to its cognate anti- $\sigma$, SpoIIAB, with residues implicated in binding to core, further supports the idea that the $\sigma$ interface with core is extensive. The simplest way for an anti- $\sigma$ to disable $\sigma$ is to occlude its interaction with core. In that case, anti- $\sigma$-binding sites should be located in our proposed core interaction regions. This proves to be the case for the three contact sites identified in $\sigma^{\mathrm{F}}$, as the equivalent residues in $\sigma^{70}$ (V385; region 2.1, P479; region 3.1 and M561; region 4.1) (Decatur and Losick 1996) are located in close proximity to residues identified here because of their defects in binding to core (V387, P504, and I565).

\section{The mutationally defined $\sigma^{70}$ interface with core is functionally specialized}

$\sigma$ mutants in three of the regions implicated in binding to core have specific additional phenotypes. Each of these phenotypes appear to be exclusively associated with that particular region of the interface. Mutations in the core interaction patch in region 2.2 also disrupt $\lambda \mathrm{Q}$ mediated anti-termination by preventing a pause very early after transcription initiation from the $\lambda \mathrm{pR}^{\prime}$ promoter (Fig. 5B) (Ko et al. 1998). This phenotype is exhib- ited only by mutants in this region of the interface. An exhaustive search for mutations allowing cells lacking ppGpp to grow on minimal medium identified only a small cluster of residues including the very residue (P504) in region 3.1 implicated in core binding, indicating that this region of the interface has a unique function in transcription. Finally, after extensive searches, only two regions of $\sigma$, located upstream and downstream of the helix-turn-helix in region 4.2, have been implicated in activator response. Our region 4.2 core-interaction patch is located within the downstream region. One of the two mutants in this region, L598, has a defect in FNR activation (Lonetto et al. 1998). The coincidence of residues conferring specific phenotypes with particular portions of the $\sigma$ interface suggests that different portions of the $\sigma$-core interface perform different, specialized functions.

The extensive information concerning recognition of the -10 region of the promoter allows us to speculate how a defect in the region 2.2 portion of the $\sigma$-core interface could lead to pausing defects. Region 2.2 is primarily composed of a helix positioned immediately behind the -10 recognition helix (Malhotra et al. 1996). The pause mediated by $\sigma$ is a consequence of its interaction with the nontemplate strand at a reiterated -10 region present early in the $p R^{\prime}$ transcript. Because core is required for the ability of $\sigma$ to discriminate between the template and nontemplate strands, the interaction of region 2.2 with core could mediate the core-induced conformational change necessary for discrimination (Marr and Roberts 1997; Callaci and Heyduk 1998). More generally, it is interesting to note that information from the nontemplate strand is utilized uniquely during the initiation process (Ring and Roberts 1994; Ring et al. 1996; Roberts and Roberts 1996). It would not be surprising to find that this portion of the $\sigma$-core interface is necessary to properly orient the nontemplate strand, so that the sequence-specific information present in this strand can be decoded.

The junctions between $\sigma$ and core are ideally positioned to communicate information concerning initiation and DNA binding from $\sigma$ to core and back. One region (3.1) is in close proximity to the initiating nucleotide and four regions $(2.2,2.4,4.1$, and 4.2$)$ are in close proximity to the two DNA-binding determinants in $\sigma^{70}$ that recognize the conserved -10 and -35 regions of the promoter (Gardella et al. 1989; Siegele et al. 1989; Severinov et al. 1994). The distance between the two DNAbinding domains of $\sigma$ increases on binding to core RNA polymerase (Callaci et al. 1999), and this may be one function of the regions of the interface adjoining the DNA-binding domains.

\section{Materials and methods}

Plasmids and DNA manipulations

Standard methods were used in plasmid construction and other DNA manipulations. Mutations in $r p o D$ were identified with Applied Biosystems BigDye Terminator Cycle Sequencing Ready Reaction Kit following the manufacturer's instructions. 
The parent plasmid for fusions of GST and $\sigma^{70}$ were variations of pGEX $\sigma[8]$ and pGEX $\sigma$ [72] (Dombroski et al. 1992). To facilitate later cloning steps, a HindIII site following the $r p o D$ gene was added to these plasmids by cloning a BglII-HindIII fragment from pJH76 into pUC21 (Vieira and Messing 1991) and then cloning the SphI-AatII fragment from the resulting plasmid (pCL357) between the same two sites in either pGEX $\sigma[8]$ or pGEXo[72] generating pCL359 and pCL361, respectively.

pCL360 was constructed by ligating an EcoRI-HindIII fragment from pCL359 between the same two sites in pET28c generating a hexahistidine-tagged variant of $\sigma^{70}$ (Novagen). pCL390 was constructed by ligating a NcoI-PstI fragment from pCL360 between the same two sites in ptrc99a (Pharmacia). A PstIHindIII fragment from pCL360 was ligated between the same two sites in pCL390. The resulting plasmid (pCL391) carries the rpoD gene and the expressed fragment includes a hexahistidine tag, a T7 tag, a thrombin cleavage site, and amino acids 8-613 of $\sigma^{70}$.

To generate mutants that relieve the toxicity of an overexpressed amino-terminal-GST fusion of $r p o D$, which lacks the first 71 amino acids of $\sigma^{70}, 10 \mathrm{ng}$ of pCL361 (expresses the toxic fusion protein, GST-Nter $\Delta 72 \sigma^{70}$ ) in $500 \mu$ l was treated with 400 mM NH$H_{2} \mathrm{OH}$ in $100 \mathrm{mM} \mathrm{KH}_{2} \mathrm{PO}_{4}$ (pH 6), 1 mM EDTA, for $1 \mathrm{hr}$ at $65^{\circ} \mathrm{C}$. Hydroxylamine was removed with the QIAquick PCR Purification Kit (Qiagen), and pCL361 was transformed into DH5 $\alpha$ via electroporation. Transformants were plated on LB containing $250 \mu \mathrm{M}$ IPTG at $37^{\circ} \mathrm{C}$. Transformants that grew on IPTG were retained for further analysis.

The QuikChange Site-Directed Mutagenesis Kit was used to make alanine substitutions in $\sigma^{70}$ following the manufacturer's instructions (Stratagene). Candidate mutants were screened for the appropriate alanine change by dideoxy sequencing.

\section{Screening of $\sigma^{70}$ mutants by SDS-PAGE}

Hydroxylamine mutants were run on denaturing gels to screen out unstable and truncated mutant sigmas. Cells were grown in LB to an O.D. of 0.5 and induced for $1 \mathrm{hr}$ with $1 \mathrm{~mm}$ IPTG. A total of $500 \mu \mathrm{l}$ of cells were spun down, the supernatant removed, the pellet resuspended in $50 \mu \mathrm{l}$ of SDS loading dye, and boiled $3-5 \mathrm{~min}$. Boiled samples $(10 \mu \mathrm{l})$ were loaded on an $8 \%$ Tris-glycine SDS-polyacrylamide gel.

\section{Ability of $\sigma^{70}$ to support cell growth}

Candidate $\sigma^{70}$-binding mutants were cloned into pCL391 (see above) and transformed into CAG20176 in which $r p o D$ is under the control of the trp promoter (Lonetto et al. 1998). Growth of CAG20176 is inhibited by tryptophan and requires indole acrylic acid (IAA). The ability of the mutants to support cell growth was determined by plating dilutions of an overnight culture grown at $37^{\circ} \mathrm{C}$ in $\mathrm{LB}$ containing $200 \mu \mathrm{M}$ IAA, on plates with or without IAA at $30^{\circ} \mathrm{C}, 37^{\circ} \mathrm{C}$, and $42^{\circ} \mathrm{C}$.

\section{Source of $\sigma$ and core enzyme}

Source of $\sigma$ and core are described for all experiments except those in Figure 4. Core polymerase was purified as described by Burgess and Jendrisak (1975) with modifications as described in Hager et al. (1990).

$\sigma^{70}$ wild-type and mutant protein was isolated from CAG20176 transformed with mutant derivatives of pCL391. Expression of the mutants was induced for $2 \mathrm{hr}$ by adding 100 $\mu \mathrm{M}$ IPTG to cultures growing exponentially at $37^{\circ} \mathrm{C}$ in LB containing $200 \mu \mathrm{M}$ IAA. Cells were harvested by centrifugation, resuspended in binding buffer $[10 \mathrm{~mm}$ Tris- $\mathrm{HCl},(\mathrm{pH} 8), 5 \%$ glyc- erol, $10 \mathrm{~mm} \beta$-mercaptoethanol, $0.5 \mathrm{M} \mathrm{NaCl}$, lysed with $150 \mu \mathrm{g}$ lysozyme $/ \mathrm{ml}$ and sonicated. The supernatant was collected by centrifugation for $60 \mathrm{~min}$ at $25,000 \mathrm{rpm}$ and applied to a $1.5-\mathrm{ml}$ Talon Metal Affinity column (Clontech). The column was washed with binding buffer containing $10 \mathrm{~mm}$ imidazole and eluted with binding buffer containing increasing concentrations of imidazole (20, 40, 80, and $150 \mathrm{~mm})$. Most of the mutants eluted in the 80 and $150 \mathrm{~mm}$ imidazole fractions. Fractions containing the mutants were dialyzed against $10 \mathrm{~mm}$ Tris- $\mathrm{HCl},(\mathrm{pH}$ 8), $50 \%$ glycerol, $10 \mathrm{~mm} \beta$-mercaptoethanol, $0.5 \mathrm{M} \mathrm{NaCl}$, and $0.05 \%$ Tween 20 and stored at $-80^{\circ} \mathrm{C}$.

\section{RNA polymerase preparation}

RNA polymerase preparation in Figure 4 is described. RNA polymerase core enzyme was reconstituted from individually overexpressed subunits. The plasmids pT $7 \alpha, \mathrm{pT} 7 \sigma$, and pMKSe 2 expressing RNAP $\alpha, \sigma^{70}$, and $\beta$ subunits, respectively, used for in vitro reconstitution experiments were as described (Zalenskaya et al. 1990; Severinov et al. 1993). The plasmid pCYB2 $\beta^{\prime}$ (Nechaev and Severinov 1999) was a source of the wild-type $\beta^{\prime}$ subunit. RNAP reconstitution was performed as described (Borukhov and Goldfarb, 1993; Tang et al. 1995). The enzymes were further purified by gel exclusion chromatography on Superose 6 (Pharmacia) and anion exchange chromatography on Resource Q (Pharmacia). Fractions containing the RNAP core were pooled, concentrated on microcentrifuge filters (Amicon) to $\sim 1 \mathrm{mg} / \mathrm{ml}$, and stored in $10 \mathrm{~mm}$ Tris- $\mathrm{HCl},(\mathrm{pH} 8), 50 \%$ glycerol, $10 \mathrm{~mm} \beta$-mercaptoethanol, $0.5 \mathrm{M} \mathrm{NaCl}$, and $0.05 \%$ Tween 20 at $-20^{\circ} \mathrm{C}$. Recombinant $\sigma^{70}$ subunit was purified from BL21(DE3) cells harboring the pT7 $\sigma$ plasmid (Zalenskaya et al. 1990) as described (Borukhov and Goldfarb 1993).

\section{Labeling $\sigma^{70}$ with $\left[\gamma^{32} P\right] A T P$ (kinase reactions)}

$\sigma^{70}$ was labeled at a naturally occurring serine protein kinase site located in the nonconserved region of $\sigma^{70}$ (RRMSI, residues 363-367) by incubating 25 units of protein kinase from bovine heart (Sigma) with $14 \mu \mathrm{M} \sigma^{70}$ and $10 \mu \mathrm{M}\left[\gamma^{-32} \mathrm{P}\right] \mathrm{ATP}(30 \mathrm{Ci} /$ pmole) in $20 \mathrm{~mm}$ Tris- $\mathrm{HCl}$ (pH 8), $100 \mathrm{~mm} \mathrm{NaCl}, 12 \mathrm{~mm} \mathrm{MgCl}_{2}$, and $10 \mathrm{~mm} \beta$-mercaptoethanol at $37^{\circ} \mathrm{C}$ for $30 \mathrm{~min}$ to $1 \mathrm{hr}$ at $37^{\circ} \mathrm{C}$. The kinase reaction was stopped by adding a $1 / 10$ volume of stop solution $\left[20 \mathrm{mM} \mathrm{NaPO}_{4}(\mathrm{pH} 8), 20 \mathrm{mM} \mathrm{P}_{2} \mathrm{O}_{7}, 100 \mathrm{~mm}\right.$ imidazole, $0.5 \%$ Tween 20, $200 \mu \mathrm{g}$ of BSA $/ \mathrm{ml}$ ] (Kaelin et al. 1992). Protein kinase was resuspended at $5 \mathrm{U} / \mu \mathrm{l}$ in $20 \mathrm{~mm}$ Tris$\mathrm{HCl}\left(\mathrm{pH}\right.$ 8), 50\% glycerol, $100 \mathrm{~mm} \mathrm{NaCl}, 12 \mathrm{~mm} \mathrm{MgCl}_{2}$, and 100 mM $\beta$-mercaptoethanol and stored at $-20^{\circ} \mathrm{C}$. Free label and kinase were removed by batch binding for $1 \mathrm{hr}$ at $4^{\circ} \mathrm{C}$ to $100 \mu \mathrm{l}$ of Ni-NTA agarose (Qiagen) in binding buffer [10 mM Tris-HCl (pH8.8), $0.5 \mathrm{M} \mathrm{NaCl}, 5 \%$ glycerol, $10 \mathrm{~mm} \mathrm{MgCl}_{2}, 10 \mathrm{~mm}$ imidazole, $1 \mathrm{~mm} \beta$-mercaptoethanol, $0.05 \%$ Tween 20 ) and washed once with binding buffer followed by two additional washes with binding buffer plus $0.5 \mathrm{~mm}$ EDTA. Labeled $\sigma^{70}$ was eluted by incubating two successive $50-\mu l$ aliquots of binding buffer plus $100 \mathrm{~mm}$ imidazole for $15 \mathrm{~min}$ each. The concentration of the labeled protein $\left(\sigma^{70^{*}}\right)$ was determined by removing a sample of the initial kinase reaction, in which the concentration of $\sigma^{70}$ is known, and comparing it with that of the two Ni-NTA elutates on an $8 \%$ Tris-glycine SDS-polyacrylamide gel with the PhosphorImager (Molecular Dynamics) to quantitate the relative amounts of labeled protein.

$\sigma$-core binding assay

$\sigma^{70}$ mutants potentially defective in $\sigma$-core interaction were tested in a competitive assay in which $\sigma^{70}$ mutants compete 
against labeled wild type $\sigma^{70}$ for core binding. The buffer used in all steps of this experiment contained $10 \mathrm{~mm}$ Tris- $\mathrm{HCl},(\mathrm{pH} 8)$, $5 \%$ glycerol, $1 \mathrm{~mm} \beta$-mercaptoethanol, $0.5 \mathrm{M} \mathrm{NaCl}, 10 \mathrm{~mm}$ $\mathrm{MgCl}_{2}$, and $200 \mu \mathrm{g} / \mathrm{ml}$ BSA. Siliconized Eppendorf tubes soaked overnight in buffer were used throughout this experiment to decrease $\sigma^{70}$ binding to the Eppendorf tubes. A total of $150 \mathrm{nM}$ wild-type $\sigma^{70^{*}}, 75 \mathrm{~nm}$ core and 0,300 , or $750 \mathrm{~nm}$ cold $\sigma^{70}$ mutant competitor were incubated at $37^{\circ} \mathrm{C}$ for $1 \mathrm{hr}$. A total of $100 \mu \mathrm{l}$ pre-equilibrated protein A-Sepharose beads (10\% volume) coupled to anti-core antibody was added to this mixture and rocked at $4^{\circ} \mathrm{C}$ for $1 \mathrm{hr}$. Polyclonal antibodies were raised in rabbits against core RNA polymerase (Animal Pharm Services). The beads were washed with $1 \mathrm{ml}$ of buffer, spun down, and the supernatant removed. A final spin, followed by aspiration, was required to remove all of the liquid from the beads and the sides of the Eppendorf tube. The dry beads were resuspended in $100 \mu 1$ of water, and $50 \mu \mathrm{l}$ of the resuspended bead solution was added to $2 \mathrm{ml}$ of scintillation fluid. Results were analyzed via scintillation counter. Coimmunoprecipitation of labeled $\sigma^{70^{*}}$ is dependent on the presence of core RNA polymerase as anti-core antibodies did not cross react with $\sigma^{70}$. All mutants were tested in at least two independent experiments performed in triplicate. Order of addition experiments performed at $0.25 \mathrm{M} \mathrm{NaCl}$ and 0.5 $\mathrm{M} \mathrm{NaCl}$ reveals that the competitive binding assay reaches equilibrium in $20 \mathrm{~min}$ at $0.5 \mathrm{M} \mathrm{NaCl}$, but is not at equilbrium at the lower salt concentration (data not shown).

\section{Determining the activity of the mutant $\sigma$ preps}

The activities of the mutant $\sigma$ preps were determined via a stalled transcription complex assay. Open complexes were assembled on the T7A1 promoter by incubating $100 \mathrm{nM} \sigma^{70}, 100$ nM core, and 200 nM DNA fragment from pCL185 (Feng et al. 1994), at $37^{\circ} \mathrm{C}$ for $15 \mathrm{~min}$ in $10 \mathrm{~mm}$ Tris- $\mathrm{HCl},(\mathrm{pH} 8), 5 \%$ glycerol, $1 \mathrm{~mm} \beta$-mercaptoethanol, $0.1 \mathrm{M} \mathrm{NaCl}, 10 \mathrm{~mm} \mathrm{MgCl}_{2}, 0.1$ mM EDTA, $0.05 \%$ Tween 20 , and $200 \mu \mathrm{g}$ of BSA/ml. Transcription was initiated and complexes were halted prior to addition of U17 by adding $250 \mu \mathrm{M}$ ApU dinucleotide; $10 \mu \mathrm{M}$ ATP, $10 \mu \mathrm{M}$ GTP, and $10 \mu \mathrm{M}\left[\alpha{ }^{32} \mathrm{P}\right] \mathrm{CTP}$ (50 Ci/ $100 \mu$ moles) were added to the mixture and incubated for an additional $10 \mathrm{~min}$. In the absence of UTP, RNA polymerase will stall at the first position requiring UTP (+17 for T7A1) (Levin et al. 1987). The labeled 16-nucleotide product was analyzed by denaturing-PAGE [7 M urea, 19\% acrylamide [acrylamide:bis 19:1 (wt/wt)] and quantitated with the PhosphorImager (Molecular Dynamics). Mutants with core-binding defects had, within twofold, the activity of wild-type $\sigma^{70}$.

In addition, some of the mutant $\sigma$ preps (V387I, D403N, E407K, P453S, and E555K) were tested for activity in a noncompetitive $\sigma$ core-binding assay performed under low-salt conditions. The buffer used in all steps of this experiment contained $10 \mathrm{~mm}$ Tris- $\mathrm{HCl}$, (pH 8), 5\% glycerol, $1 \mathrm{~mm} \beta$-mercaptoethanol, $0.1 \mathrm{M} \mathrm{NaCl}, 10 \mathrm{~mm} \mathrm{MgCl}$, and $200 \mu \mathrm{g} / \mathrm{ml}$ BSA. Siliconized Eppendorf tubes were used throughout this experiment to decrease $\sigma^{70}$ binding to the Eppendorf tubes. A reaction containing $100 \mathrm{~nm}$ mutant or wild-type $\sigma^{70^{*}}$ (labeled as described previously) and $2 \mu \mathrm{M}$ core was incubated at $37^{\circ} \mathrm{C}$ for $1 \mathrm{hr}$, then $100 \mu \mathrm{l}$ of pre-equilibrated protein A-Sepharose beads (10\% volume) coupled to anti-core antibody was added to this mixture and rocked at $4^{\circ} \mathrm{C}$ for $1 \mathrm{hr}$. Polyclonal antibodies were raised in rabbits against core RNA polymerase (Animal Pharm Services). The beads were washed with $1 \mathrm{ml}$ of buffer, spun down, and the supernatant removed. A final spin, followed by aspiration, was required to remove all of the liquid from the beads and the sides of the Eppendorf tube. The dry beads were resuspended in $100 \mu \mathrm{l}$ of SDS loading dye, and boiled for $10 \mathrm{~min}$. A total of $20 \mu \mathrm{l}$ of the resuspended bead solution was run on an $8 \%$ Tris-glycine SDSpolyacrylamide gel. Results were analyzed via PhosphorImager (Molecular Dynamics). Coimmunoprecipitation of labeled $\sigma^{70^{*}}$ is dependent on the presence of core RNA polymerase as anticore antibodies did not cross react with $\sigma^{70}$. All mutants were tested in at least two independent experiments performed in duplicate.

\section{Peptides}

Synthetic $\sigma$ factor $(\mathrm{SF})$ peptides were synthesized by standard automated FMOC chemistry. The peptide sequences were as follows (single letter amino acid code): IAKKYTNRGLQFLDLIQE (SF2.4, corresponds to $\sigma^{70}$ amino acids 390-407), IAKKYTNRGLQFLNLIQE (SF2.4-D403N), IAKKYTNRGLQFDLIAE (SF2.4-Q406A), and IAKKYTNRGLQFLDLIQK (SF2.4-E407K). The substitutions are in boldface type in the three peptides. The peptides used were at least $90 \%$ pure as judged by reverse-phase HPLC.

\section{Abortive initiation assay}

For abortive initiation analysis (used in Fig. 4), 0.2 pmole of core RNA polymerase was incubated with or without SF2.4 peptide for $5 \mathrm{~min}$ at $37^{\circ} \mathrm{C}$ in $20 \mu \mathrm{l}$ of $20 \mathrm{~mm}$ Tris- $\mathrm{HCl}(\mathrm{pH} 8.0), 40 \mathrm{~mm}$ $\mathrm{KCl}$, and $10 \mathrm{mM} \mathrm{MgCl}_{2}$, then 0.1 pmole of the purified $\sigma^{70}$ was added and incubated for an additional $5 \mathrm{~min}$ at $37^{\circ} \mathrm{C}$. Abortive initiation reactions were started by adding $20 \mathrm{ng}$ of a 130-bp DNA fragment containing T7A1 promoter (Severinov et al. 1993), $0.5 \mathrm{~mm}$ initiating ribodinucleotide CpA, and $10 \mathrm{mCi}$ of $\left[\alpha-{ }^{32} \mathrm{P}\right] \mathrm{UTP}$ (3000 Ci/mmole, New England Nuclear) and were allowed to proceed for $15 \mathrm{~min}$ at $37^{\circ} \mathrm{C}$. Reactions were terminated by the addition of an equal volume of urea-loading buffer, resolved by urea-PAGE [ $7 \mathrm{M}$ urea, $20 \%$ polyacrylamide, acrylamide to bis 19:1 (wt/wt)], and revealed by PhosphorImager (Molecular Dynamics).

\section{Native polyacrylamide gel shift assay}

RNAP core enzyme ( 0.2 pmole) was combined with 0.1 pmole of $\sigma^{70}$ and incubated $5 \mathrm{~min}$ at $37^{\circ} \mathrm{C}$ to allow formation of holoenzyme. Where indicated, SF2.4 was added just prior to $\sigma^{70}$. Reactions were transferred to ice and supplemented with $\sim 5000$ cpm of ${ }^{32} \mathrm{P}$ 5'-labeled 130-bp DNA fragment containing T7A1 promoter. After incubation on ice for $30 \mathrm{~min}$, the reactions were loaded on a $0.5 \times \mathrm{TBE}$ nondenaturing $4 \%$ polyacrylamide gel [acrylamide/bis 39:1 (wt/wt)] kept at $4^{\circ} \mathrm{C}$ and RNAP-promoter complexes were revealed by PhosphorImager (Molecular Dynamics).

\section{Promoter-proximal pause measured in vitro}

The percent of promoter-proximal-paused complexes for $\sigma^{70}$ mutants was determined as described in Ko et al. (1998).

\section{Acknowledgments}

We thank Robert Landick for helpful discussions and critical reading of the manuscript; Jon Tupy for critical reading of the manuscript, help with figure preparation, and computer modeling; Tracy Cao for critical reading of the manuscript; Dan Joo and Christian N. Parker for helpful discussions; Tanja Gruber for helpful discussions and sharing unpublished results; and Ding Jun for providing anti-core antibody. This work was supported by the National Institutes of Health (NIH) (GM30477). 
M.M.S. was supported in part by National Science Foundation. C.L.C. was supported by NIH (GM16603). M.T.M. and J.W.R. were supported by NIH (21941). K.S. and S.N. were supported by $\mathrm{NIH}$ (GM59295) and a Burroughs Wellcome Fund Career Award.

The publication costs of this article were defrayed in part by payment of page charges. This article must therefore be hereby marked "advertisement" in accordance with 18 USC section 1734 solely to indicate this fact.

\section{References}

Borukhov, S., and A. Goldfarb. 1993. Recombinant Escherichia coli RNA polymerase: Purification of individually overexpressed subunits and in vitro assembly. Protein Expression Purif. 4: 1-8.

Burgess, R. and J. Jendrisak. 1975. A procedure for the rapid, large-scale purification of Escherichia coli DNA-dependent RNA polymerase involving polymin $\mathrm{P}$ precipitation and DNA-cellulose chromatography. Biochemistry. 14: 4634.

Callaci, S. and T. Heyduk. 1998. Conformation and DNA binding properties of a single-stranded DNA binding region of $\sigma^{70}$ subunit from Escherichia coli RNA polymerase are modulated by an interaction with the core enzyme. Biochemistry 37: 3312-3320.

Callaci, S., E. Heyduk, and T. Heyduk. 1999. Core RNA polymerase from E. coli induces a major change in the domain arrangement of the $\sigma^{70}$ subunit. Mol. Cell. 3: 229-238.

Cliften, P.F., J.-Y. Park, B.P. Davis, S.-H. Jang, and J.A. Jaehning. 1997. Identification of three regions essential for interaction between a $\sigma$-like factor and core RNA polymerase. Genes \& Dev. 11: 2897.

Decatur, A.L. and R. Losick. 1996. Three sites of contact between the Bacillus subtilis transcription factor $\sigma^{\mathrm{F}}$ and its anti- $\sigma$ factor SpoIIAB. Genes \& Dev. 10: 2348-2358.

Dombroski, A.J., W.A. Walter, M.T. Record Jr., D.A. Siegele, and C.A. Gross. 1992. Polypeptides containing highly conserved regions of transcription initiation factor $\sigma^{70}$ exhibit specificity of binding to promoter DNA. Cell 70:501-512.

Dombroski, A.J., W.A. Walter, and C.A. Gross. 1993. Aminoterminal amino acids modulate $\sigma$-factor DNA-binding activity. Genes \& Dev. 7: 2446-2455.

Feng, G., D.N. Lee, D. Wang, C.L. Chan, and R. Landick. 1994. GreA-induced transcript cleavage in transcription complexes containing Escherichia coli RNA polymerase is controlled by multiple factors, including nascent transcript location and structure. J. Biol. Chem. 269: 22282-22294.

Gardella, T., H. Moyle, and M. Susskind. 1989. A mutant Escherichia coli $\sigma^{70}$ subunit of RNA polymerase with altered promoter specificity. J. Mol. Biol. 206: 579-590.

Hager, D., D. Jin, and R. Kornberg. 1990. Use of Mono Q highresolution ion-exchange chromatography to obtain highly pure and active Escherichia coli RNA polymerase. Biochemistry 29: 7890-7894.

Helmann, J.D. and M.J. Chamberlin. 1988. Structure and function of bacterial sigma factors. Annu. Rev. Biochem. 57: 839-872.

Hernandez, V.J. and M. Cashel. 1995. Changes in conserved region 3 of Escherichia coli $\sigma^{70}$ mediate ppGpp-dependent functions in vivo. J. Mol. Biol. 252: 536.

Ingraham, J.L., O. Maaloe, and F.C. Neidhardt. 1983. Growth of the bacterial cell. Sinauer Associated Inc., Sutherland, MA.

Ishihama, A. 1991. Control of cell growth and division. Springer, Heidelberg, Germany.

Joo, D.M., N. Ng, and R. Calendar. 1997. A $\sigma^{32}$ mutant with a single amino acid change in the highly conserved region 2.2 exhibits reduced core RNA polymerase binding specificity. Proc. Natl. Acad. Sci. 94: 4907-4912.

Joo, D.M., A. Nolte, R. Calendar, Y.N. Zhou, and D.J. Jin. 1998. Multiple regions on the Escherichia coli heat shock transcription factor $\sigma^{32}$ determine core RNA polymerase binding specificity. I. Bacteriol. 180: 1095-1102.

Kaelin, W.G., W. Krek, W.R. Sellers, J.A. DeCaprio, F. Ajchembaum, C.S. Fuchs, T. Chittenden, Y. Li, P. Farnham, and M.A. Blanar. 1992. Expression cloning of a cDNA encoding a retinoblastoma-binding protein with E2F-like properties. Cell 70: 351-364.

Ko, D.C., M.T. Marr, J. Guo, and J.W. Roberts. 1998. A surface of Escherichia coli $\sigma^{70}$ required for promoter function and antitermination by phage $\lambda \mathrm{Q}$ protein. Genes \& Dev. 12: 3276-3285.

Leonetti, J.-P. and E.P. Geiduschek. 1998. Core-sigma interaction: Probing the interaction of the bacteriophage T4 gene 55 promoter recognition protein with E. coli RNA polymerase core. EMBO J. 17: 1467-1475.

Lesley, S.A. and R.R. Burgess. 1989. Characterization of the Escherichia coli transcription factor sigma 70: Localization of a region involved in the interaction with core RNA polymerase. Biochemistry 28: 7728-7734.

Lesley, S.A., M.A.D. Brow, and R.R. Burgess. 1991. Use of in vitro protein synthesis from polymerase chain reaction-generated templates to study interaction of Escherichia coli transcription factors with core RNA polymerase and for epitope mapping of monoclonal antibodies. J. Biol. Chem. 266: $2632-2638$.

Levin, J.R., B. Krummel, and M.J. Chamberlin. 1987. Isolation and properties of transcribing ternary complexes of Escherichia coli RNA polymerase positioned at a single template base. J. Mol. Biol. 196: 85-100.

Lonetto, M., M. Gribskov, and C. Gross. 1992. The $\sigma^{70}$ Family: Sequence conservation and evolutionary relationships. $J$. Bacteriol. 174: 3843-3849.

Lonetto, M.A., V. Rhodius, K. Lamberg, P. Kiley, S. Busby, and C. Gross. 1998. Identification of a contact site for different transcription activators in region 4 of the Escherichia coli RNA polymerase $\sigma^{70}$ subunit. J. Mol. Biol. 284: 1353-1365.

Malhotra, A., E. Severinova, and S.A. Darst. 1996. Crystal structure of a $\sigma^{70}$ subunit fragment from $E$. coli RNA polymerase. Cell 87: 127-136.

Marr, M.T. and J.W. Roberts. 1997. Promoter recognition as measured by binding of polymerase to nontemplate strand oligonucleotide. Science 276: 1258-1260.

Nagai, H. and N. Shimamoto. 1997. Regions of the Escherichia coli primary sigma factor $\sigma^{70}$ that are involved in interaction with RNA polymerase core enzyme. Genes Cells 2: 725-734.

Nechaev S. and K. Severinov. 1999. Inhibition of Escherichia coli RNA polymerase by bacteriophage T7 gene 2 protein. $J$. Mol. Biol. 289: 815-826.

Osawa, T. and T. Yura. 1981. Effects of reduced amount of RNA polymerase sigma factor on gene expression and growth of Escherichia coli: Studies of the rpoD40 (Amber) mutation. Mol. \& Gen. Genet. 184: 166-173.

Polyakov, A., E. Severinova, and S.A. Darst. 1995. Three-dimensional structure of E. coli core RNA polymerase: Promoter binding and elongation conformations of the enzyme. Cell 83: $365-373$.

Ring, B.Z. and J.W. Roberts. 1994. Function of a nontranscribed DNA strand site in transcription elongation. Cell 78: 317324.

Ring, B.Z., W.S. Yarnell, and J.W. Roberts. 1996. Function of E. coli RNA polymerase $\sigma$ factor $\sigma^{70}$ in promoter-proximal 
Sharp et al.

pausing. Cell 86: 485-493.

Roberts, C.W. and J.W. Roberts. 1996. Base-specific recognition of the nontemplate strand of promoter DNA by E. coli RNA polymerase. Cell 86: 495-501.

Severinov K., M. Soushko, A. Goldfarb, and N. Nikiforov. 1993. Rifampicin region revisited. New rifampicin-resistant and streptolydigin-resistant mutants in the beta subunit of Escherichia coli RNA polymerase. J. Biol. Chem. 268: 1482014825.

Severinov, K., D. Fenyo, E. Severinova, A. Mustaev, B.T. Chait, A. Goldfarb, and S.A. Darst. 1994. The $\sigma$ subunit conserved region 3 is part of " 5 '-face" of active center of Escherichia coli RNA polymerase. J. Biol. Chem. 269: 20826-20828.

Shuler, M.F., K.M. Tatti, K.H. Wade, and C.P. Moran Jr. 1995. A single amino acid substitution in $\sigma^{\mathrm{E}}$ affects its ability to bind core RNA polymerase. J. Bacteriol. 177: 3687-3694.

Siegele, D., J. Hu, W. Walter, and C. Gross. 1989. Altered promoter recognition by mutant forms of the $\sigma^{70}$ subunit of Escherichia coli RNA polymerase. J. Mol. Biol. 206: 591603.

Tang H., K., Severinov, A. Goldfarb, and R. Ebright. 1995. Rapid RNA polymerase genetics: One-day, no-column preparation of reconstituted recombinant Escherichia coli RNA polymerase. Proc. Nat1. Acad. Sci. 92: 4902-4906.

Tintut, Y. and J.D. Gralla. 1995. PCR mutagenesis identifies a polymerase-binding sequence of sigma 54 that includes a sigma 70 homology region. J. Bacteriol. 177: 5818-5825.

Vieira, J. and J. Messing. 1991. New pUC-derived cloning vectors with different selectable markers and DNA replication origins. Gene 100: 189-194.

Wilson, C. and A.J. Dombroski. 1997. Region 1 of $\sigma^{70}$ is required for efficient isomerization and initiation of transcription by Escherichia coli RNA polymerase. J. Mol. Biol. 267: 60-74.

Wosten, M.M.S.M. 1998. Eubacterial $\sigma$-factors. FEMS Microbiol. Rev. 22: 127-150.

Zalenskaya K., Lee J., Gujuluva C., Shin Y., Slutsky M., and A. Goldfarb. 1990. Recombinant RNA polymerase: inducible overexpression, purification, and assembly of Escherichia coli rpo gene products. Gene 89: 7-12.

Zhou, Y. and C. Gross. 1992. How a mutation in the gene encoding $\sigma^{70}$ suppressed the defective heat shock response caused by a mutation in the gene encoding $\sigma^{32}$. J. Bacteriol. 174: $7128-7137$. 


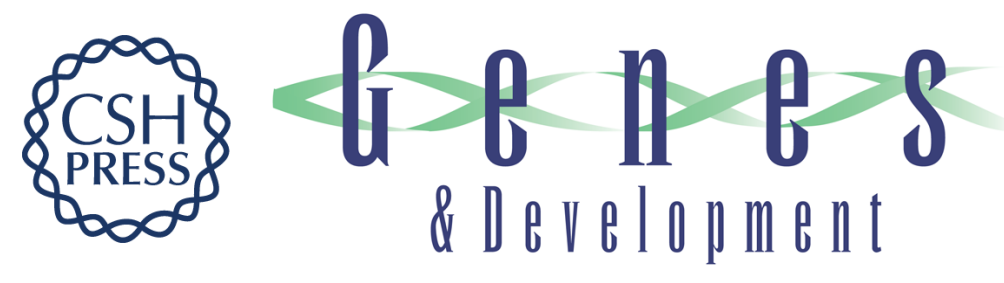

\section{The interface of $\varsigma$ with core RNA polymerase is extensive, conserved, and functionally specialized}

Meghan M. Sharp, Cathleen L. Chan, Chi Zen Lu, et al.

Genes Dev. 1999, 13:

References This article cites 43 articles, 17 of which can be accessed free at:

http://genesdev.cshlp.org/content/13/22/3015.full.html\#ref-list-1

License

Email Alerting Receive free email alerts when new articles cite this article - sign up in the box at the top Service right corner of the article or click here.

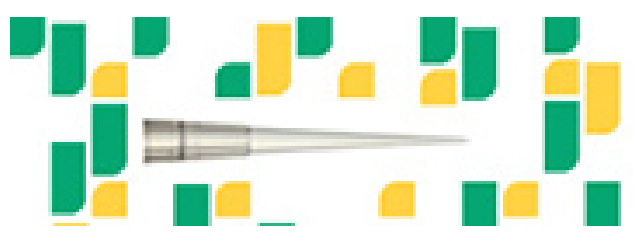

Focused on your science. 